\title{
Modelling, Analysis and Development of Progressive Die for Seat Rail
}

\author{
A. Padma Rao ${ }^{1 *}$, Manzoor $\mathrm{Hadi}^{2}$ \\ ${ }^{1}$ Department of Mechanical Engineering, B. V. Raju Institute of Technology, Narsapur, Telangana 502313, India \\ ${ }^{2}$ Department of Mechanical Engineering, B. V. Raju Institute of Technology, Narsapur, Telangana 502313, India
}

\begin{abstract}
Progressive dies are highly used in batch productions where product variety is low. The progressive die is also called follow on die. It performs series of basic sheet metal operations. There are two or more stations and work piece is gradually shaped to final product through passing each of these stations. The 'progression' (advance or pitch) is linear travel of the strip stock at each press stroke and it is equal to the infestation distance. In the present paper an attempt is made to develop a new progressive die, which used in making seat rail of an automotive fourwheeler vehicle of Toyota, to optimize the use of material. So, the cost of progressive die reduces without losing its quality. For modelling CATIA and for analysis ANSYS are used.
\end{abstract}

\section{Introduction}

Most of the expensive cast, forged, and machined products are replaced with sheet metal parts. The architectural equipment which are made by hand are substituted by the processes like metal stamping, extrusion, forging. It is quite easy to make these elements compare to hand made. There are also other methods like metal tubing, forming and drawing. These are more often used and more expensive. The most useful products of modern technology are metal stampings. Sometimes the riveting and other fastening processes are replaced by sheet metal stamping which can also be used to improve the existing designs that often are costly. Stamping process is applicable in automotive, aerospace and constructional industries.

The dies are used in the stamping process. Progressive stamping die is a special type of precision tool that cuts and forms sheet metal according to the required shape. Sometimes it is fully automated.

\section{Literature Survey}

There have been many experiments conducted and theoretical work done in design and analysis of progressive dies. For production of different parts, different types of progressive dies are designed. The following is a review of the research that has been completed in progressive die.

Jyothi Bhaskar et al. [1] performed die design and analysis of progressive tool for can lid lever. Mathematical correlations are also calculated. Finite element analysis in this process boundary conditions are load on punch and die. CATIA is used for modelling, assembly and drafting analysis is done in ANSYS.

Ulhas K. Annigeri et al. [2] proposed design and development of progressive tool for manufacturing washer press tool. In this paper design and fabrication of progressive press tool for production of washer has been developed and press tool has tried out on a mechanical type of press. Raja Shakarappa [3] worked on "Analysis and simulation of progressive die" without compromising on the quality of output. By using different analysis software the stress deformation of die are analyzed. V.S. Bhajantri et al. [4] conducted analysis of progressive die for optimizing the resources used in design and manufacturing a progressive die. Software named COSMOS is used for analysis which uses finite element method for solution. Md Inaithul Rehaman et al. [5] worked on modelling and analysis of progressive die used in chain link plate. CATIA and ANSYS are used in this work for design and analysis the stress distribution. Professor K.P. Kattimani et al. [6] investigated design and analysis of progressive tool for moving contact holder. Critical parts of progressive tool are analysed for better functioning during the production of component. D. K. Kushwaha [7] addressed the industrial problem occurred in shells. In first phase it is explained the design of die tool and checked the induced stresses. In second phase the of the work it is developed the die and punch assembly. Harshal A Chavan et al. [8] made the modelling and analysis of progressive die tool for fabricating the tail gate striker used in head lamp assembly. Narayan Chouhan et al. [9] done the design and analysis of progressive tool which assistance the industry to manufacture the part rather than outsourcing which leads to save money. A. Balaraju et al. [10], designed and analyzed the finned brake drum by using FEA.

Deepak [11] analyzed, manufactured and assembled the progressive die to produce mold tool component.

\section{Progressive Die}

Progressive dies are a mixture of various single dies operating as different stations and grouped into the same die shoe. These stations are positioned to follow a sequence of operations needed to produce the required part. Progressive die is a multiple station die. 


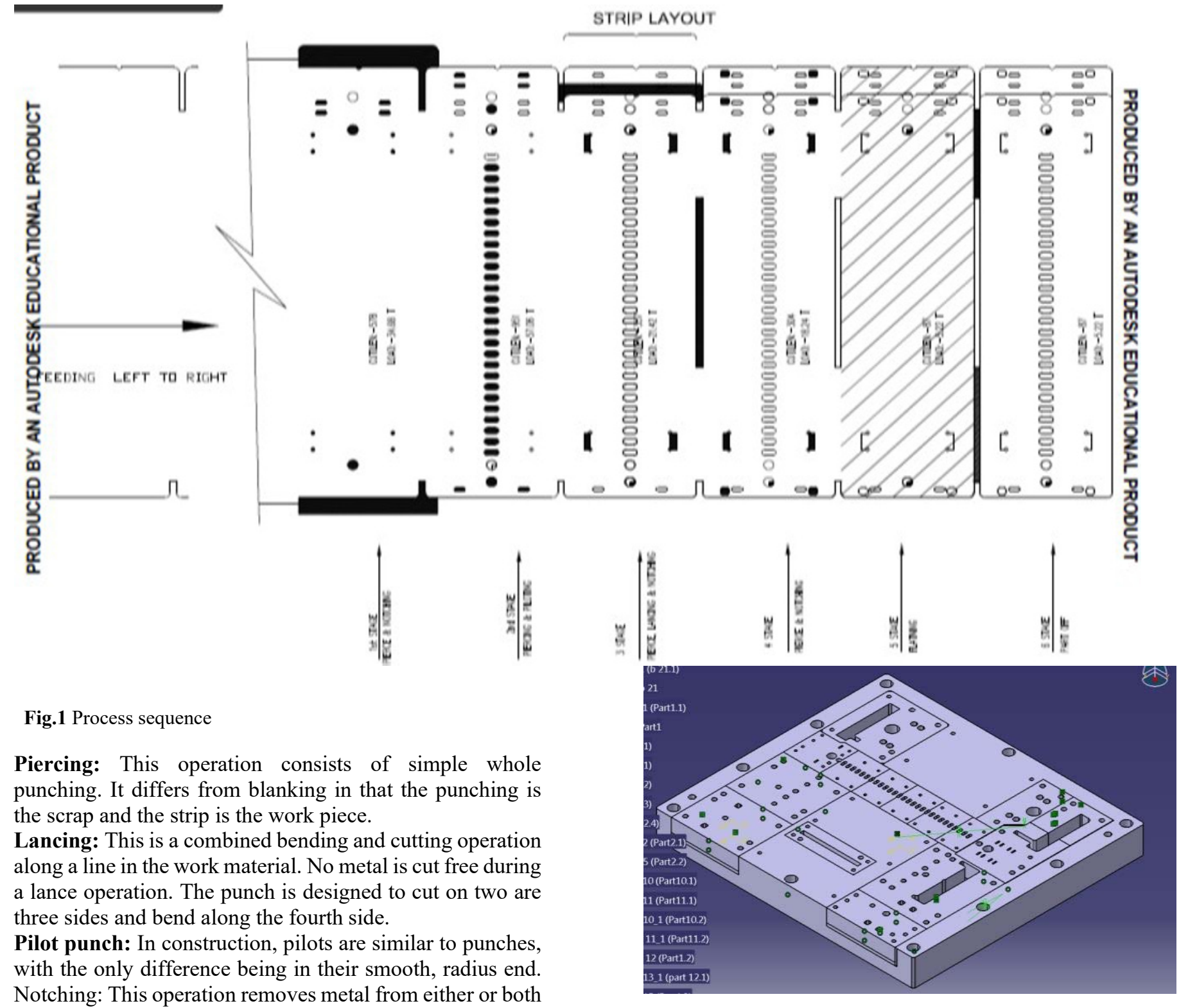

Fig. 3 Die Plate

\subsection{Parts of progressive tool:}
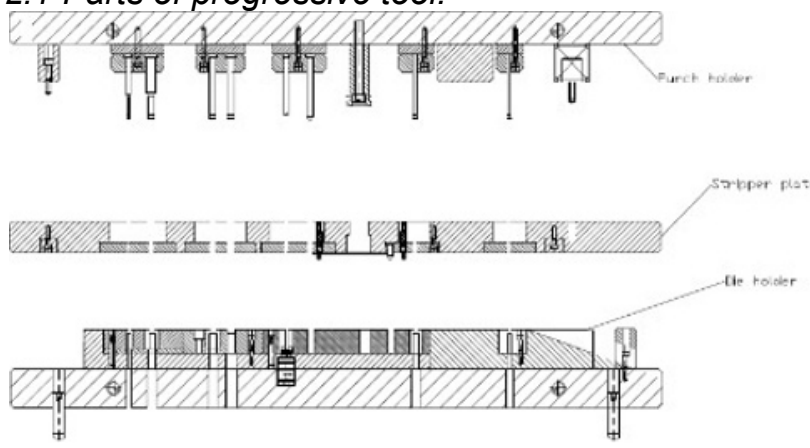

Fig.2 Progressive die

Die plate: The profile of a die is cut with the help of the die block. Typically, it is the lower member of the tool which provides cutting edge.

Punch plate: Punch plate is also known as punch holder, which holds various cutting and non-cutting punches to ensure alignment between punch and die.

Stripper plate: The main roll of the stripper is to remove the stock from the punch after performing the piercing and banking operations. The stripper plate is shown in Fig. 4.

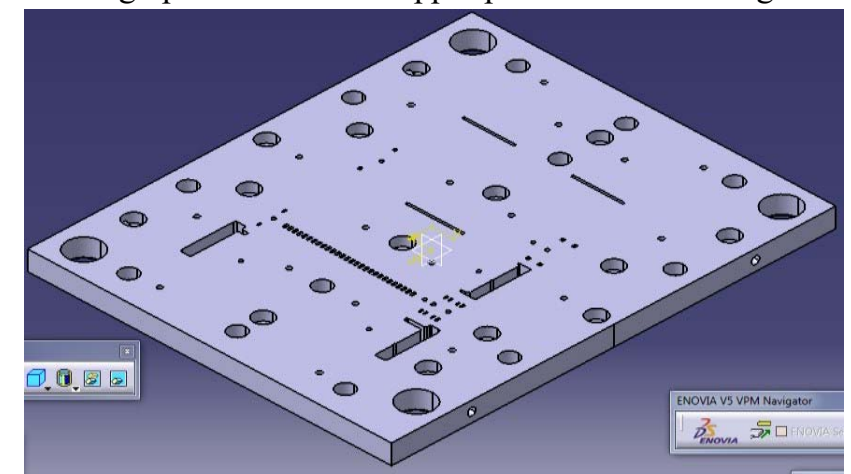

Fig.4 Stripper plate 


\section{Material selection for tool dies:}

D2 Steel: D2 steel is an air-hardening die steel, abrasion resistance, high in hardness, and resistance to deformation. The machinability of this material is quite good and also may be still improved by a slightly greater amount of sulphur within the material makeup. The material's machinability and surface finish are improved considerably by well-dispersed particles of sulphide. Heat treating to a lower hardness positively affects the material's toughness. Forging dies or other die-related tooling are made by D2 steel.

Elastic modulus: $215 \mathrm{kN} / \mathrm{mm}^{2}$; Yield stress: $450 \mathrm{MPa}$; Tensile strength: $750 \mathrm{MPa}$; Compressive Yield stress: $22 \times 10^{8} \mathrm{~Pa}$

\section{Calculations}

Press tonnage $=1.2 \times$ total force

Cutting force, $\mathrm{F}=\mathrm{S} \times \mathrm{P} \times \mathrm{T}$

Table 1. Shear force of different punches

\begin{tabular}{|c|c|c|c|c|c|}
\hline $\begin{array}{l}\mathrm{S} \\
\mathrm{t} \\
\mathbf{a} \\
\mathrm{t} \\
\mathrm{i} \\
\mathrm{o} \\
\mathrm{n} \\
\mathrm{s}\end{array}$ & Operation & $\begin{array}{c}\text { Nu } \\
\text { mb } \\
\text { er } \\
\text { of } \\
\text { op } \\
\text { era } \\
\text { tio } \\
\text { ns }\end{array}$ & $\begin{array}{l}\text { Perim } \\
\text { eter } \\
(\mathbf{m m})\end{array}$ & $\begin{array}{l}\text { Shear } \\
\text { force }(N)\end{array}$ & $\begin{array}{l}\text { She } \\
\text { ar } \\
\text { forc } \\
\text { e }\end{array}$ \\
\hline \multirow{5}{*}{1} & Punch hole & 8 & 18.84 & 37378.56 & 3.84 \\
\hline & Punch hole & 2 & 51.96 & 25541.98 & 2.6 \\
\hline & Oblong & 4 & 22.36 & 22181.12 & 2.26 \\
\hline & Notching & 1 & 208.15 & 5161.2 & 5.26 \\
\hline & Notching & 1 & 145.30 & 36034.4 & 3.67 \\
\hline \multirow{3}{*}{2} & Punch hole & 2 & 57.96 & 25541.98 & 2.6 \\
\hline & Oblong & 6 & 22.36 & 33271.68 & 3.39 \\
\hline & Notching & 28 & 29.02 & $\begin{array}{l}201515.8 \\
8\end{array}$ & $\begin{array}{l}20.5 \\
4\end{array}$ \\
\hline \multirow{3}{*}{3} & Notching & 1 & 319.80 & 79310.4 & 8.08 \\
\hline & Notching & 1 & 118.10 & 29288.8 & 2.98 \\
\hline & Lancing & 4 & 21.76 & 21585.92 & 2.20 \\
\hline 4 & Punching & 6 & 2306 & 35206.08 & 3.59 \\
\hline \multirow{2}{*}{5} & Notching & 1 & 172.20 & 42705.6 & 4.35 \\
\hline & Notching & 1 & 220.20 & 54609.6 & 5.56 \\
\hline
\end{tabular}

Material $=$ MS

$\mathrm{F}_{\mathrm{n}}=\mathrm{n} \times \mathrm{S} \times \mathrm{P} \times \mathrm{T}$

where

$\mathrm{F}_{\mathrm{n}}=$ cutting force for ' $\mathrm{n}$ ' operations

$\mathrm{n}=$ number of operations

$\mathrm{T}=$ thickness $=0.80 \mathrm{~mm}$;

$\mathrm{S}=$ Stress $=310 \mathrm{~N} / \mathrm{mm}^{2}$;

$\mathrm{P}=$ Perimeter $=\pi \mathrm{d}$;

Total shear force $=$ sum of all forces $\quad=70.891 \mathrm{~T}$

Stripping force $=10 \%$ of total shear force $=7.0891 \mathrm{~T}$

Total press capacity $\quad=764722.56 \mathrm{~N}$

Press tonnage $=1.2 \times$ total press capacity $=93.576 \mathrm{~T}$

Table 2. Deflection of different punches

\begin{tabular}{|l|l|l|l|l|}
\hline Tool & $\begin{array}{l}\mathbf{F}=\mathbf{8 0} \% \\
\text { cutting force } \\
(\mathbf{N})\end{array}$ & $\begin{array}{l}\text { Length } \\
(\mathbf{L}) \\
(\mathbf{m m})\end{array}$ & $\begin{array}{l}\text { Area } \\
\text { Moment of } \\
\text { inertia (I) } \\
\mathbf{m m}^{4}\end{array}$ & $\begin{array}{l}\text { Deflecti on } \\
(\mathbf{\delta})(\mathbf{m m})\end{array}$ \\
\hline Piercing punch 1 & 10216.792 & 90 & 52.81 & 0.0808 \\
\hline Piercing punch 2 & 3737.856 & 90 & 7.06 & 0.2210 \\
\hline Slot punch 1 & 4436.22 & 90 & 139.76 & 0.0132 \\
\hline Slot punch 2 & 5757.59 & 90 & 267.641 & 0.0009 \\
\hline Die plate 1 & 478407.608 & 558 & 7716325 & 0.2609 \\
\hline Die plate 2 & 77747.12 & 558 & 3642129 & 0.0898 \\
\hline
\end{tabular}




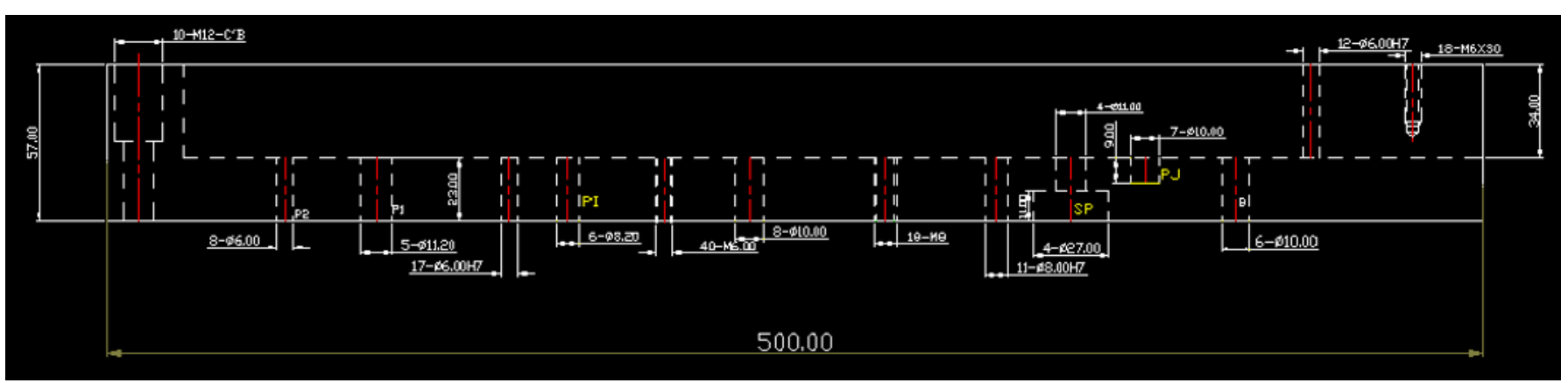

Fig.5 Die plate in 2D drawing

\section{Design and Modelling}

The Fig. 6 shows the design and modelling of different tools used in progressive die. The design and modelling are done as per the requirement of the Toyota automotive four-wheeler vehicle.

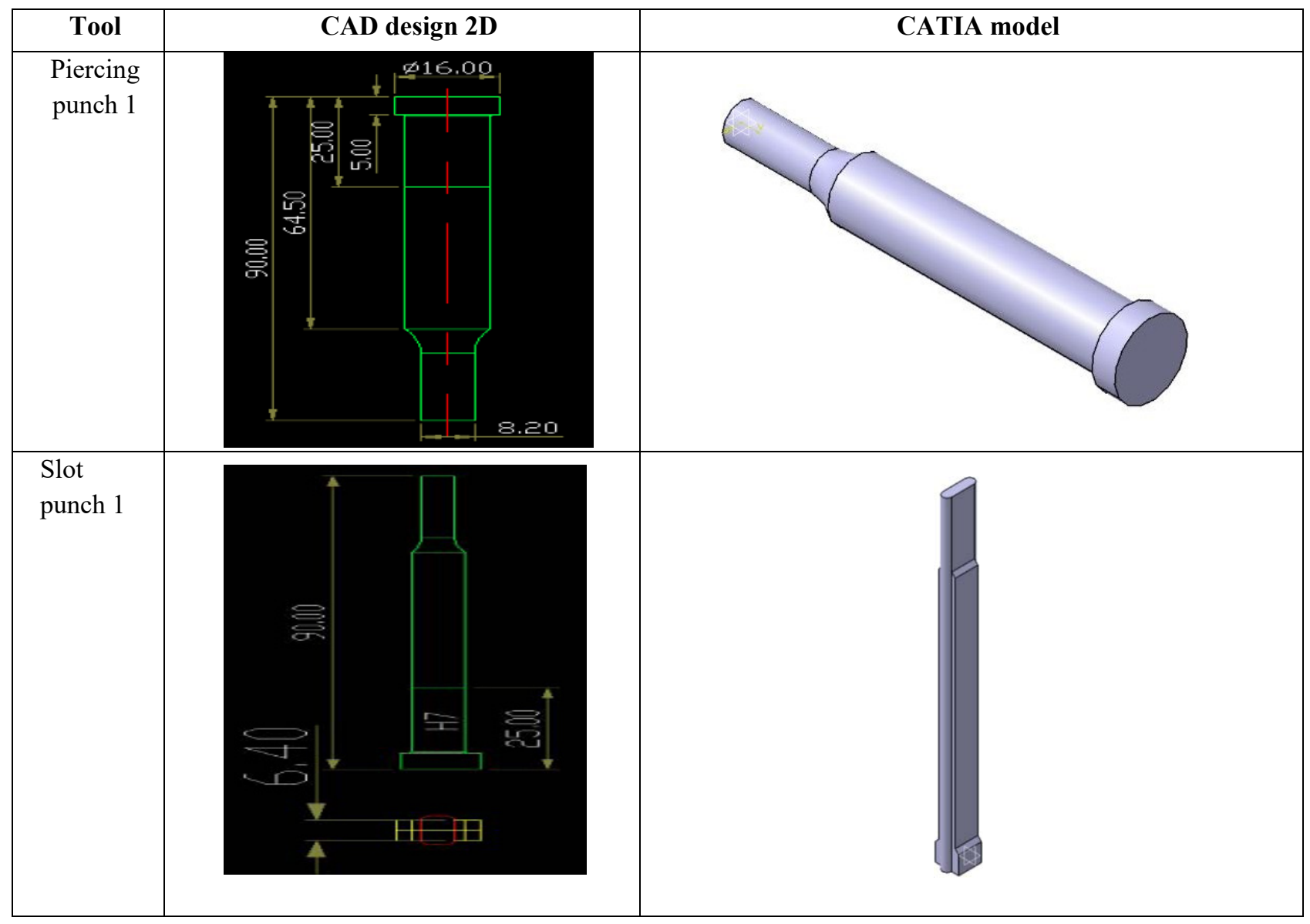




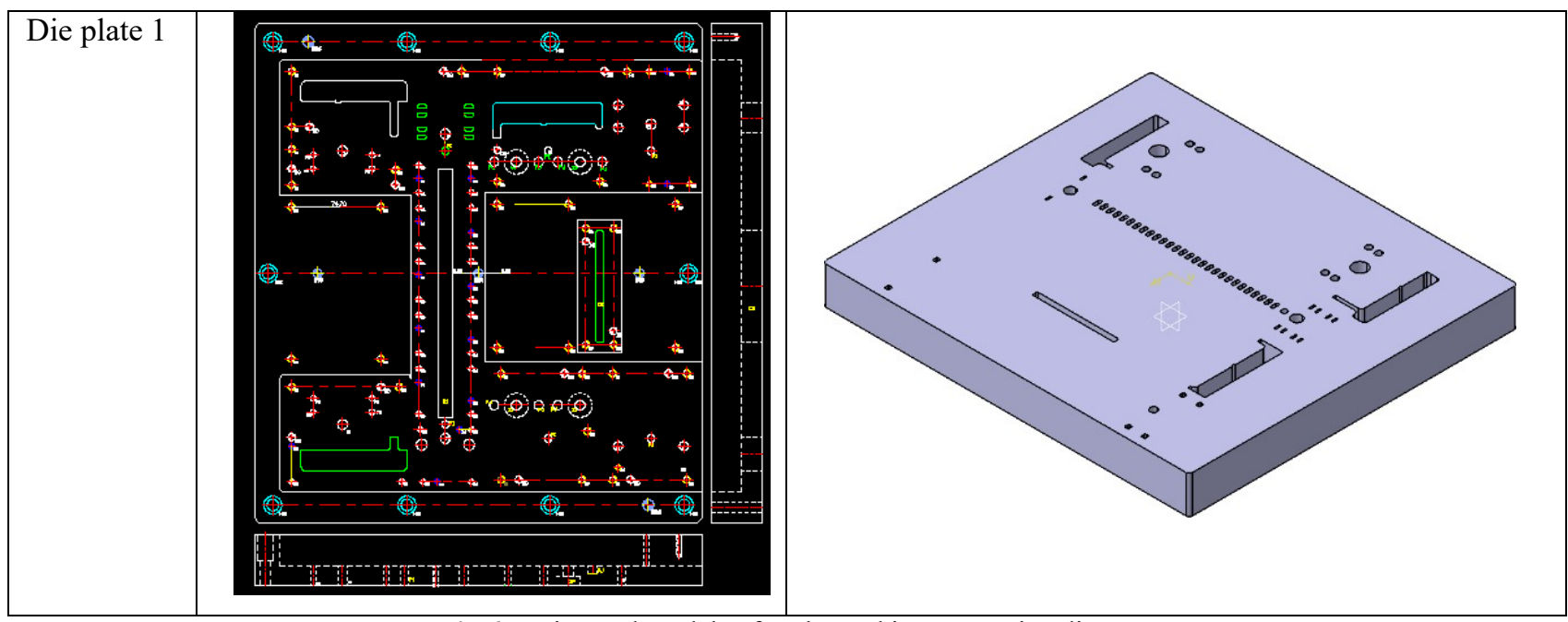

Fig.6 Design and models of tools used in progressive die

\section{Analysis}

The Fig. 7 shows the analysis of different tools used in

progressive die. The stress and deformation occurred in the components are shown.

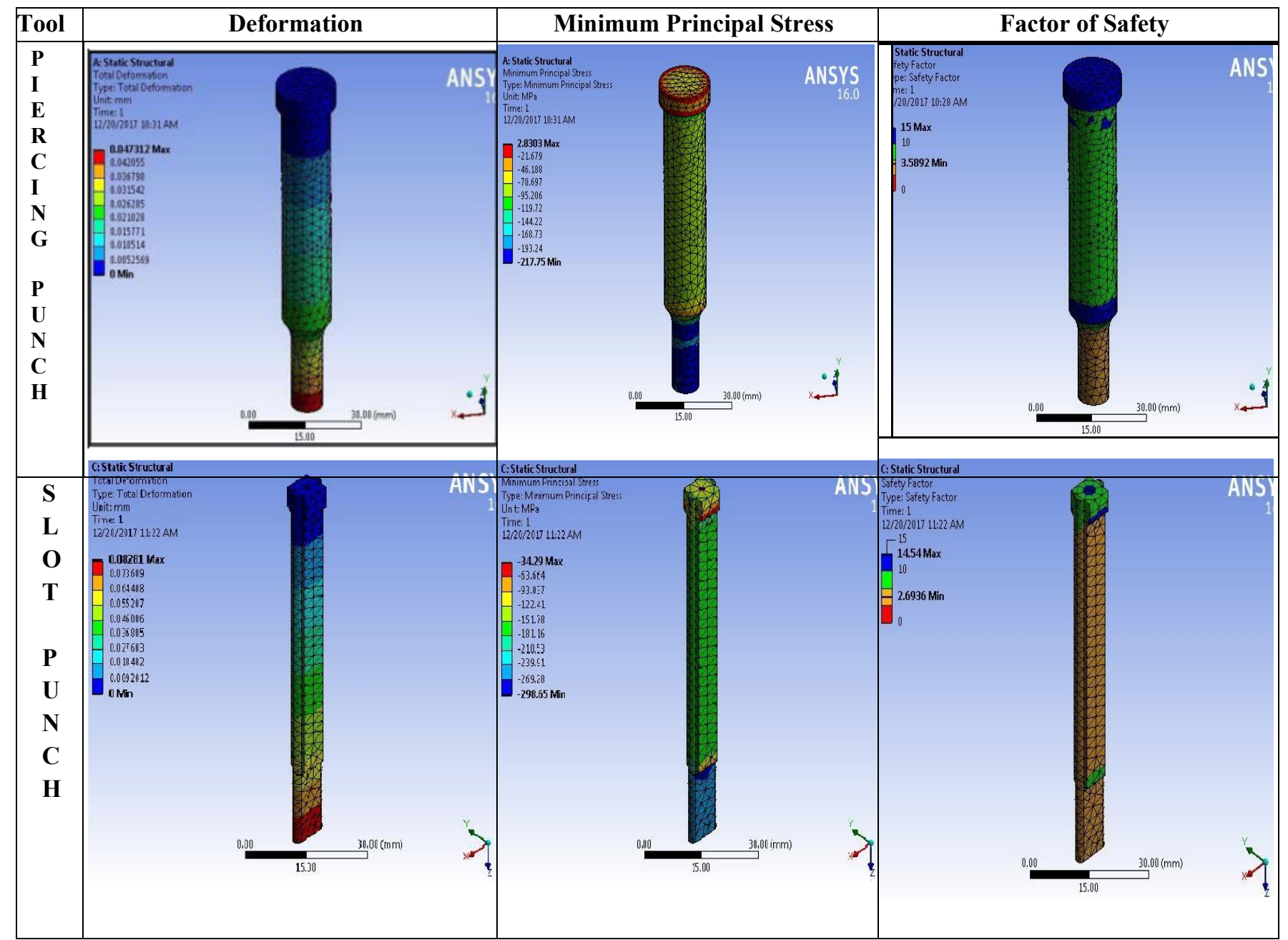



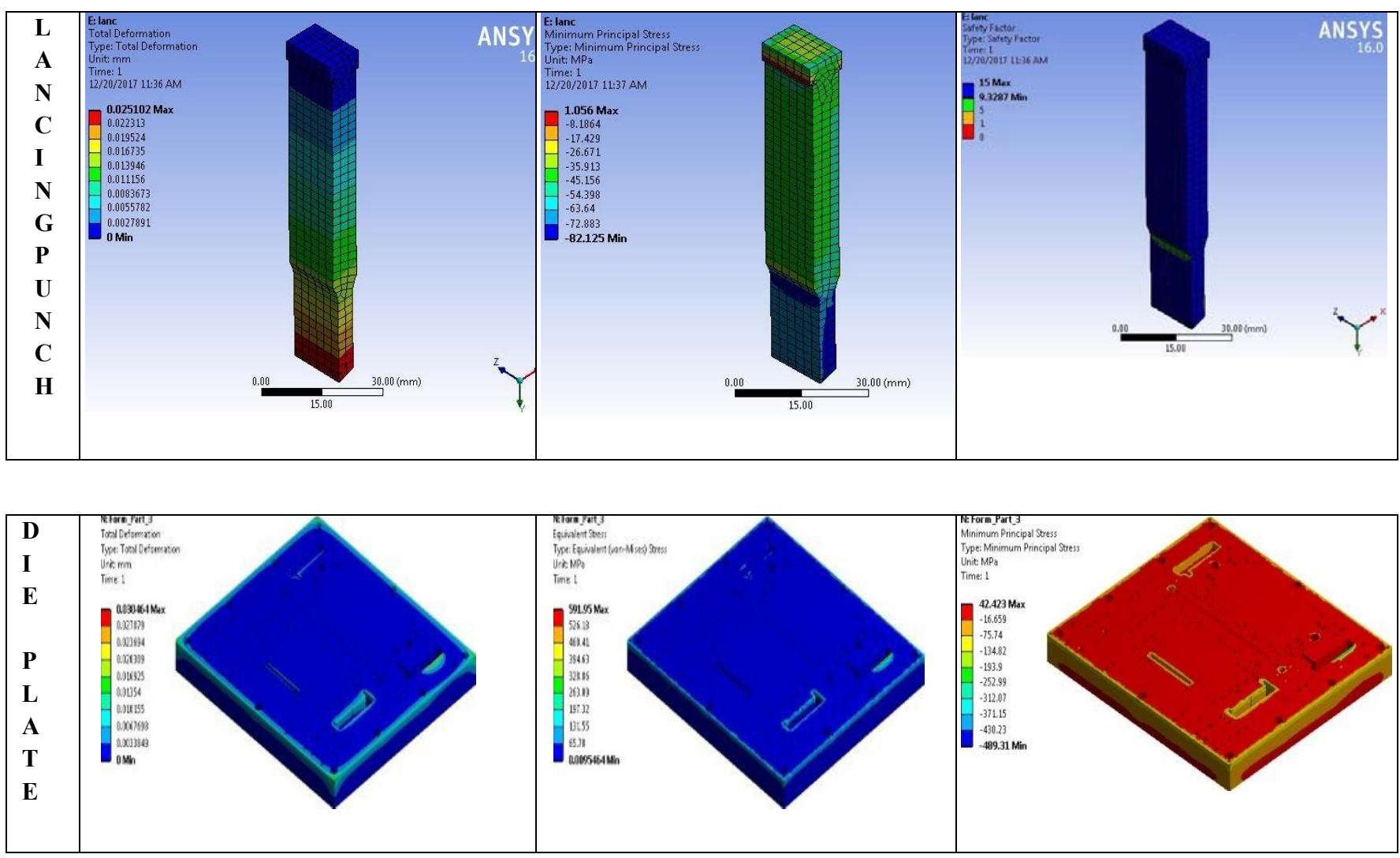

Fig.7 Stress plots and deformation of different punches

\section{Development of New Die}

The Fig. 8 shows the fabrication process of the rail of an automobile. progressive die which is used for making the seat

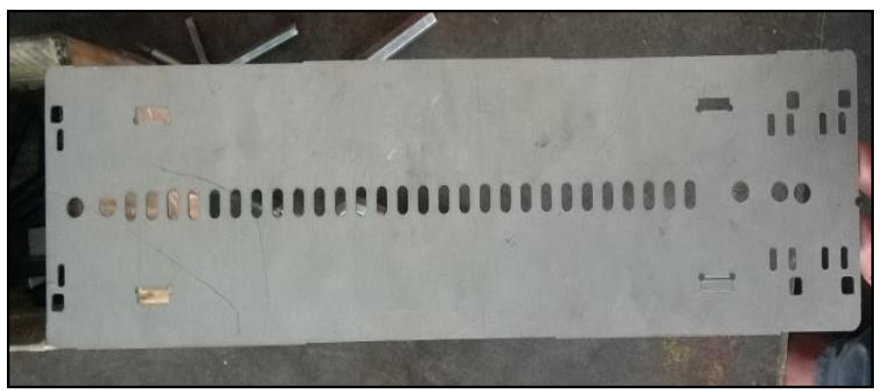

(a)

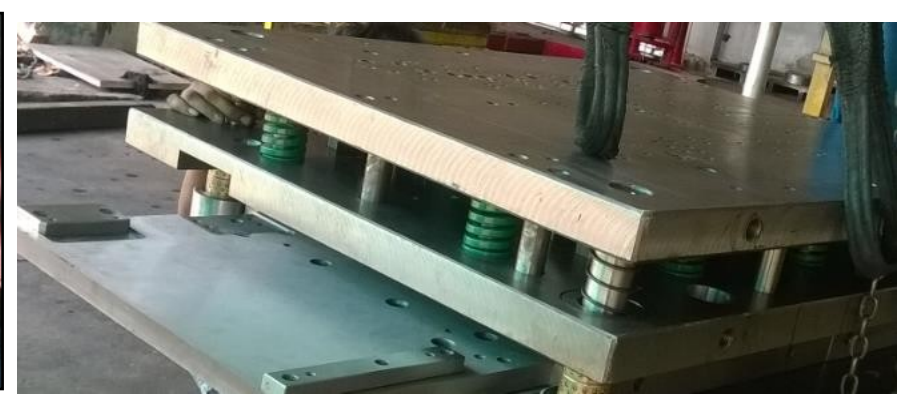

(b) 


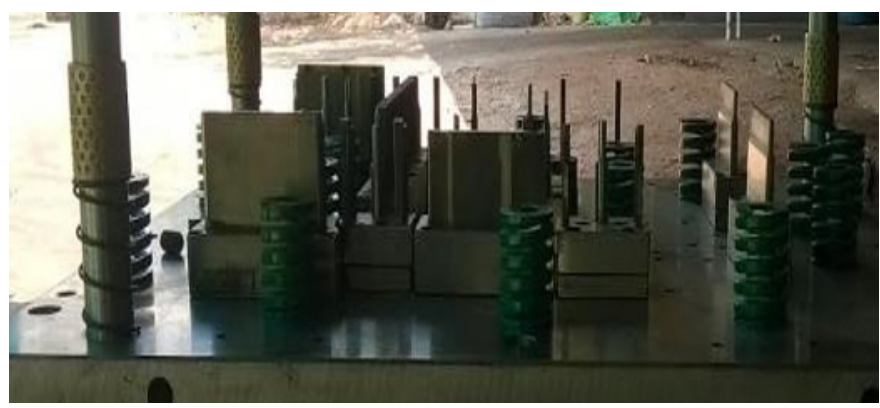

(c)

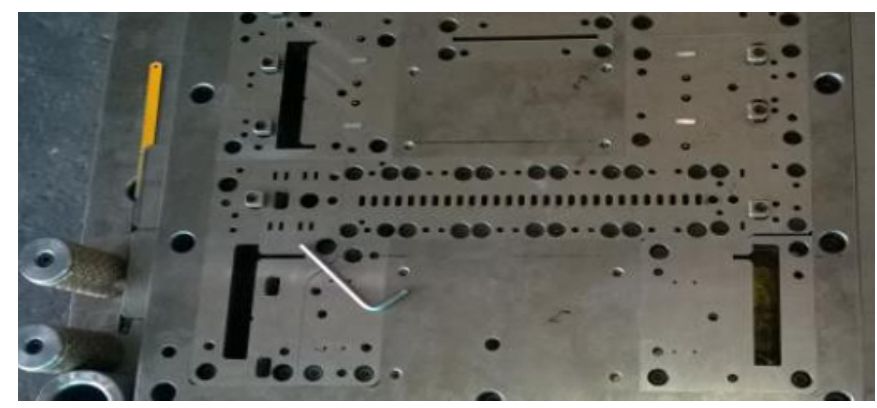

(e)

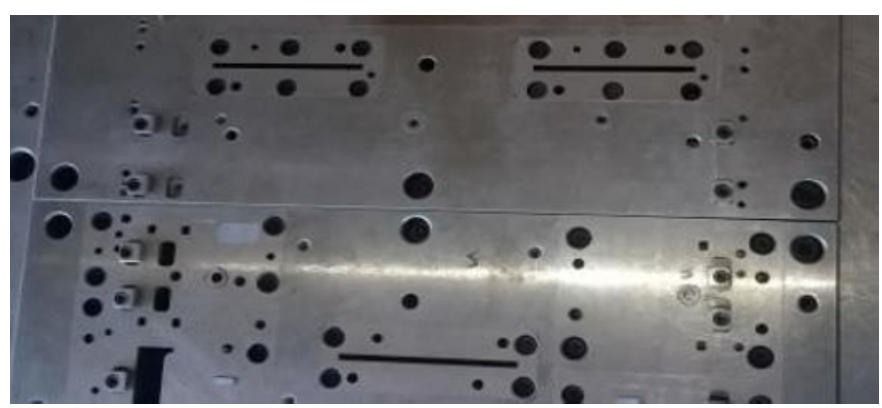

(d)

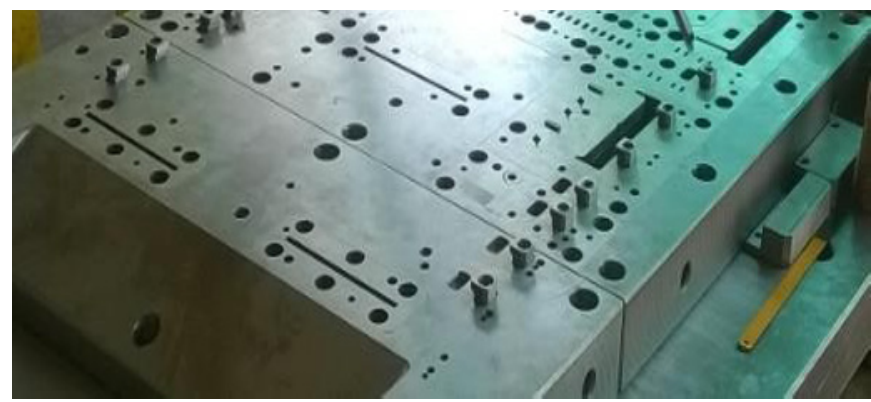

(f)

Fig.8 Fabricated progressive die

\section{Results and Discussion}

Table 3. FEM simulation and calculated results

\begin{tabular}{|l|l|l|l|}
\hline \multicolumn{1}{|c|}{ Part } & $\begin{array}{c}\text { Theoretical } \\
\text { deformation } \\
(\mathbf{m m})\end{array}$ & $\begin{array}{l}\text { Computed } \\
\text { deformation } \\
\text { (FEA) } \\
(\mathbf{m m})\end{array}$ & $\begin{array}{l}\text { Minimum } \\
\text { Principal } \\
\text { Stress } \\
\mathbf{( M P a )}\end{array}$ \\
\hline Piercing punch 1 & 0.0815 & 0.047 & 217.75 \\
\hline Piercing punch 2 & 0.221 & 0.086 & 515.93 \\
\hline Slotting punch 1 & 0.0132 & 0.082 & 298.65 \\
\hline Slotting punch 2 & 0.0009 & 0.031 & 106.06 \\
\hline Lancing Punch & - & 0.025 & 82.15 \\
\hline Die 1 & 0.2609 & 0.0304 & 489.31 \\
\hline Die 2 & 0.0898 & 0.0103 & 286 \\
\hline
\end{tabular}

\section{Conclusions}

The significant conclusions that may be drawn based on the above results may be summarized as follows.

1. Results obtained in deformation through $\mathrm{F} E$ analysis are more or less the same as theoretical values.

2. As all the parts are subjected to minimum compressive stress, one can take compressive yield stress of the material as safe stress. Therefore, all the stresses obtained are under allowable stresses.

3. Deformation starts mostly at the tips of punch. Crack initiation might also take place at these edges, since the edges are sharp.

4. Creep is general occurrence in these types of cases.

5. By providing back plates in punch holders, few stresses can be relieved.

Progressive die is most economically viable way in batch production. Production rate is high in progressive dies as it is a continuous operation. Since every punch and die is assembled individually, it is easy to replace them. This reduces the maintenance cost despite its high cost. 


\section{References}

[1] Jyothi Bhaskar, G Sathya Prakash., International Journal of Research in Engineering \& Advanced Technology, Volume 1, Issue 4, Aug-Sept, 2013

[2] Ulhas K Annigeri, Raghavendra Ravi Kiran K, Y P Deepthi, AIP Conference, Vol. 1859, Issue 1, July 2017.

[3] Raja Shakarappa, International Journal of Research in Engineering and Technology, Volume: 03 Special Issue: 03, May 2014

[4] V. S. Bhajantri, G. B. Kapashi, S. C. Bajantri, International Journal of Engineering and Innovative Technology, Volume 3, Issue 7, January 2014.

[5] Md Inaithul Rehaman, P Satish Reddy, Matta Manoj, N.Guru Murthy, International Journal of Science Engineering and Advance Technology, IJSEAT, Vol 2, Issue 11, Nov-2014

[6] K. D. Kattimani, R. K. Tavildar, P. K. Kakamari, International Journal of Emerging Technologies and Innovative Research, Vol. 2, Issue 6, 2015.

[7] D. K. Kushwaha, S. Banwait, Husain Mehdi, IJAPIE, Vol. 2, 65-70, 2017.

[8] Harshal A Chavan, Vijay P Wani, Journal of Physics, Volume 1240, 2019.

[9] Narayan Chouhan, N Manjunath Gowda, Satish Kumar S, International Research Journal of Engineering and Technology, Vol. 6, Issue 9, 2019.

[10] A. BalaRaju, A. Padma Rao, and Chiranjeevi, AIP Conference Proceedings, Vol. 2358, Issue 1, 2021.

[11] V. Deepak, O. Abhilash, Y. P. Ravitej, Veerachari, and L. Abhinandan, AIP Conference Proceedings, Vol. 2316, 2021. 